\title{
Surface-Mediated Reactions of Uranyl Peroxide Materials U60 and Studtite at the Mineral-Electrolyte Interface
}

\author{
BEN GEBARSKI ${ }^{1}$ AND UDO BECKER ${ }^{2}$
}

${ }^{1}$ University of Michigan

${ }^{2}$ University of Michigan, Dept. of geol. Sciences

Presenting Author: bbge@umich.edu

The electrochemical and adsorption behavior of the trace element $U$ in uranium-60 nanoclusters $\left(\mathrm{U}_{60}\right)$, a spherical cluster of uranyl polyhedra (pictured below), has yet to be fully characterized since its first synthesis in 2005. Our initial studies on $\mathrm{U}_{60}$ and its naturally-occurring analogue, studtite (pictured below), focus on characterizing the redox switching in both compounds $\left(\mathrm{U}^{6+}\right.$ to $\mathrm{U}^{5+}$ and $\left.\mathrm{U}^{4+}\right)$ using electrochemical methods. Structural changes in cluster and sheet topologies as a function of redox state was then investigated using atomic force microscopy (AFM), scanning electron microscopy (SEM), and auger electron spectroscopy (AES) coupled with in situ electrochemical methods.

As the interaction of radionuclides with mineral interfaces is known to play an important role in their transport within the environment, this study considers the fundamental adsorption behavior of uranyl peroxides on naturally occurring minerals as predicated by their ability to reduce to $\mathrm{U}^{4+}$, thus providing insight into the mobility of actinide species capable of similar redox reactions. An understanding of the molecular-scale interfacial reactivity requires direct observations of the interface composition and structure using electrochemical Atomic Force Microscopy (EC-AFM).

Results show that precipitates form upon addition of solute, and grow in volume at oxidizing potentials, while reducing potentials lead to the re-dissolution of precipitates and eventual corrosion of the surface.

These results demonstrate the feasibility of these techniques to study uranyl peroxide behavior at the mineral-fluid interface in environmental conditions. 